\title{
Restauración de la pintura sobre lienzo "Virgen de Gracia"
}

\section{Lucía Sameño Puerto \\ Restauradora}

Este lienzo, anónimo del siglo XVIII, forma parte del conjunto monumental de la Puerta de Córdoba de Carmona y representa a la Virgen de Gracia, patrona de esta localidad. Su ubicación en este lugar expuesto al exterior, se debe a la funcionalidad devocional pues los carmonenses le rezaban antes de salir de peregrinación.

La composición resulta muy simple en comparación con otras representaciones del mismo tema. La Virgen está ubicada en el centro sobre una peana y en el interior de una arquitectura entre dos columnas, unidas por un arco de medio punto.

La pintura está realizada al óleo sobre un soporte de lienzo de lino, constituido por dos piezas quedando la costura situada horizontalmente en el centro.

La obra fue restaurada en el año 1973. Los datos de este trabajo figuran en una nota que estaba situada en el reverso de la obra. Esta intervención afectó tanto al soporte como a la película pictórica. Dicho documento revela que el soporte fue adherido a un tablex reforzado con una estructura perimetral a modo de bastidor.

En el examen preliminar no se presentaban signos de desadherencias entre el lienzo y la madera y la estructura de refuerzo no sufría alteraciones.

La superficie pictórica se encontraba muy desgasta$\mathrm{da}$, concretamente en las zonas oscuras, debido a limpiezas anteriores y a través de estos desgastes podemos apreciar la preparación de color rojizo. Se observan también, dos quemaduras superficiales debidas a la cercanía de faroles de velas.

El tratamiento de Conservación-Restauración, se llevó a cabo después de realizar un estudio previo del estado de conservación mediante el examen visual de la misma. Previamente a su intervención se documentó gráficamente mediante técnicas físicas de examen para el conocimiento del campo visible y no visible, realizadas por el Departamento de Análisis del Instituto.

\section{Análisis fotográfico}

Se toman fotografías con luz normal y luz rasante general y de detalles. Y luz ultravioleta general y de detalles.

\section{Análisis químico}

Se tomaron muestras de los estratos pictóricos, de la preparación, del tipo de barniz y de las fibras textiles. La intervención se ha centrado en el tratamiento de la superficie pictórica, se ha respetado la adhesión de la tela al soporte de tablex porque se ha mantenido estable. Otra manipulación podría ser perjudicial para la obra.

Se eliminaron depósitos superficiales, tanto del anverso como del reverso, mediante limpieza mecánica con brocha y aspiradora.

Previamente a la limpieza de la película pictórica, se han realizado varios tests de solubilidad de disolventes y micro catas de limpieza, para la obtención de las mezclas de disolventes más adecuadas a las características de los materiales a eliminar.

En una primera fase de limpieza se elimina el barniz oxidado extendido por toda la superficie pictórica. En la segunda fase se retiran tanto repintes como estucos que invaden parte de la pintura original. Concretamente, en la zona de la costura, se ha recuperado pintura original y se ha reconstruido el dibujo del brocado de la ropa de la Virgen.

En los bordes hay un total de dieciocho clavos que unen el tablex al bastidor. Éstos se han lijado y protegido con Paraloid B72.

Posteriormente algunas lagunas se han estucado y otras se han quedado con la preparación que tenían de intervenciones anteriores, por encontrarse en buen estado.

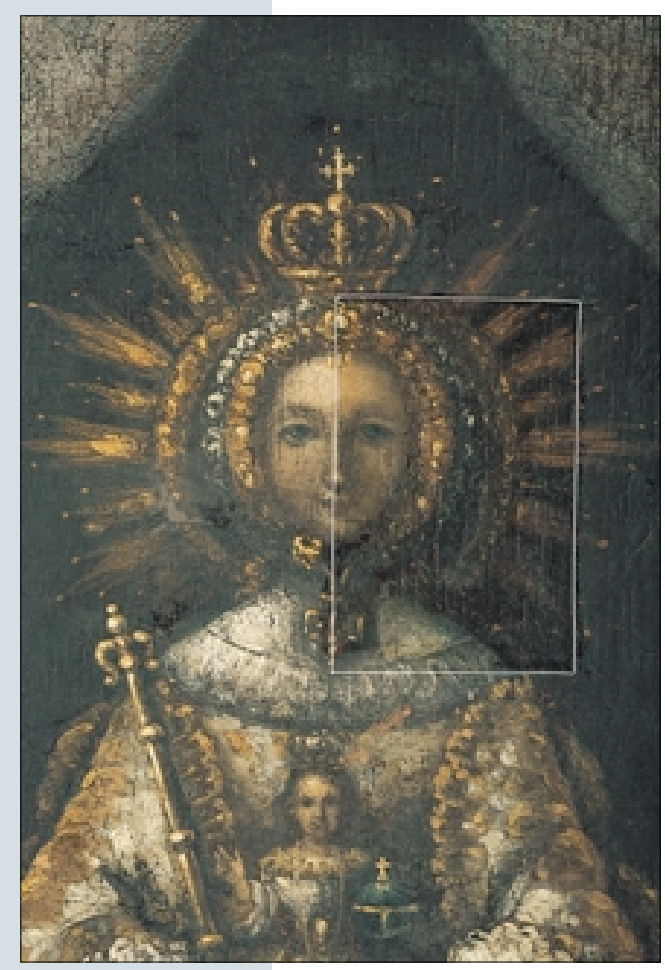

La reintegración cromática de estas lagunas se ha realizado en primer lugar con técnica acuosa, y después se ha aplicado una capa de barniz extendido por toda la superficie.

En la fase final se ha reintegrado con pigmentos al barniz y se ha aplicado una última capa de protección con barniz pulverizado. 